\title{
Extensive cervical epidural abscess: case report
}

\begin{abstract}
Background: Spinal epidural abscess is very irritating annoying problems that get the emergent proper decision is a must. Its presence within the cervical spine is life threating issue because of the vital functions that can be compromised as a result from just the compression effect. So the concept of the bony decompression is essential in such cases.
\end{abstract}

Study design: To describe a rare presentation of spinal epidural abscess

Patients and Methods: A case report of an extensive epidural abscess within the cervical spinal region.

Results: Case report of cervical epidural abscess in 56 year old male from Rosetta complained of acute onset of neck pain for about 2 months with progressive course of upper and lower limbs weakness with no sphincter affection. No previous neck and back surgery. History of renal impairment and on medical treatment for about 4 years. Magnetic Resonance imaging of the cervical spine showing ventral cervical spinal cord compression by an epidural abscess extending from the apex of dens to the level of C5. Surgical intervention via anterior approach and corpectomy of the $\mathrm{C} 4$ and $\mathrm{C} 5$, iliac crest graft with plate and screws fixation was done. About 3 months after surgery, the patient markedly improved and was able to perform the usual lifestyle activities.

Conclusion: Diagnosing patient with epidural abscess within the cervical spine is somewhat is a difficult suspecting issue in patient with no history of chronic illness nor previous spine surgery. Evacuation of the abscess and corpectomy of the friable pathological levels, fusion with iliac crest graft and fixation with plate and screws was a suitable option in management of this case.

Keywords: cervical, epidural abscess, corpectomy

\author{
Volume 7 Issue 6 - 2017
}

\author{
Mohamed E Elsebaey, Mohamed Elgohary \\ Department of Neurosurgery, Damanhour Medical National \\ Institute, Egypt
}

\begin{abstract}
Correspondence: Mohamed E Elsebaey, Department of Neurosurgery, Damanhour Medical National Institute, Damanhour, Egypt, Email seba3y700025@gmail.com
\end{abstract}

Received: October 01, 2017 | Published: November 07, 2017

\section{Background}

Cervical epidural abscesses are rare conditions but particularly life threating. ${ }^{1,2}$ Many risk factors and comorbidities can ease the suspicion of its diagnosis. ${ }^{2,3}$ Medical antibiotic therapy plus surgical evacuation are mandatory in most of the cases especially who suffered from motor deficits. The early diagnosis and management result in better prognosis. ${ }^{3}$

\section{Case report}

56 year old male from Rosetta complained of acute onset of neck pain for about 2 months with progressive course of upper limbs weakness with no sphincter affection. No previous dental nor neck nor back surgery nor acupuncture. History of renal impairment and on medical treatment for about 4 years. Body temperature was about 38.2 C. Physical examination showed marked mid neck tenderness, no palpable masses were felt, no lymph nodes were felt. Neurological examination revealed grade 3 paraparesis in the upper limbs while grade zero in both lower limbs on Medical Research Council (MRC) scale. Preservation of the deep sensation while loss of the superficial sensation, positive Hoffman sign and positive planter reflex. Magnetic Resonance imaging of the cervical spine showing ventral cervical spinal cord compression by an epidural abscess extending from the apex of dens to the level of C5. Decreased spinal canal diameter and mild spinal cord compression were present (Figure 1).

Under general anesthesia, the patient was placed in supine position, with head slightly rotated to the left side, longitudinal skin incision was done on the right side of neck, dissection in layers and vertebral levels were marked using the fluoroscopy. Longus colli muscle was divided, corpectomy of $\mathrm{C} 4$ and $\mathrm{C} 5$ and opening the intervertebral foramina with kerrison were done. Excision of the posterior longitudinal ligament and evacuation of pus. Yellowish purulent semiliquid material was drained and isolated from the surgical field as much as possible, then was sent later after the surgery into histopathological analysis and culture. Gorgeous irrigation with saline. Iliac crest graft was harvested then placed in site of $\mathrm{C} 4$ and $\mathrm{C} 5$ then internal fixation with plate and screws was done (Figure 2). For rinsing and draining, Suction drain was implanted and left for 4 days.

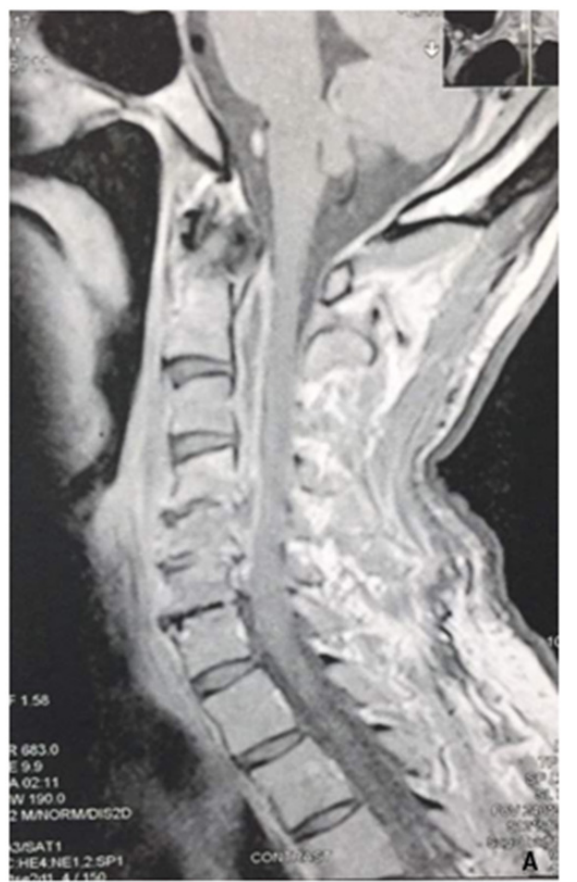




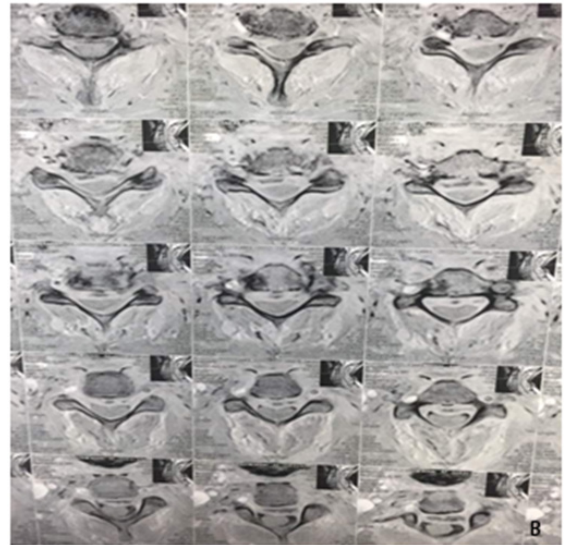

Figure I (A) Preoperative MRI cervical spine contrasted TWI sagittal view (B) preoperative MRI cervical spine contrasted TWI axial view. Both are showing ring thick wall enhanced oblonged mass ventral to the cervical spinal cord and extending from apex of C2 till C6 with obliteration of the subarachnoid space.

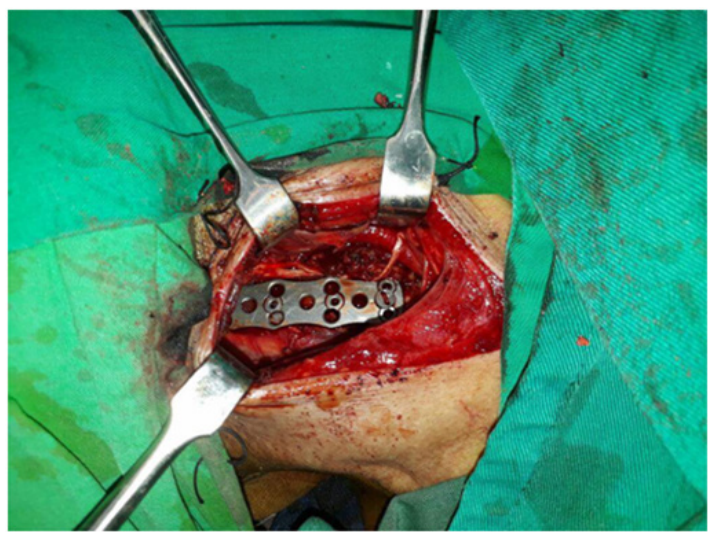

Figure 2 Intraoperative image showing the plate and fixating screws after placing on the anterior aspect of the cervical vertebrae through anterior approach.

Postoperative cervical -X- ray was performed to assess the position and accuracy of the graft and instrumentation insertion. Intravenous antibiotic therapy was administrated and maintained for 12 weeks while he was discharged from hospital one week after the operation. Rigid cervical collar was applied for 7 weeks for providing neck stabilization, decreasing pain, prevent kyphotic deformity and avoid any instrumentation device pull out.

Staphylococcus aureus was revealed as the organism of this drained pus in our patient. About 5 days after the operation, an extensive course of rehabilitation and physiotherapy was begun. about 3 months after surgery, the patient was able to perform the usual lifestyle activities after marked neurological improvement in the motor power of both upper and lower extremities up to MRC grade 5 at the $5^{\text {th }}$ month postoperative, but the neck pain was still be present in mild degree. Serial radiographs were done when the follow-up visits for ensuring the fusion and position of the internal fixation system (Figure 3).

\section{Discussion}

The clinical significance of patients of epidural abscess is that the increased neurological complications in such patients have an adverse effect on prognosis. ${ }^{4,5}$ The most valuable radiological technique in the diagnosis of spinal epidural abscess is MRI due to its high resolution power and ability to characterize the tissues. ${ }^{6}$ Hyperintense signal in the MRI, obliteration of the subarachnoid space and mild cord compression were observed. ${ }^{6}$ Infectious or tumoural causes and complications secondary to trauma, tuberculous spondylitis, and brucellosis may be considered in differential diagnosis., Laboratory investigations were also done like random, fasting and post prandial blood glucose level for detection of diabetes mellitus as immunosuppressed patients are more susceptible for spinal abscesses and osteomyelitis. Blood culture and tube agglutination tests, all were negative. CRP level was 150 . White blood cells count was 11.800 Treatment options include antibiotic therapy and surgical drainage. ${ }^{6,8,9}$

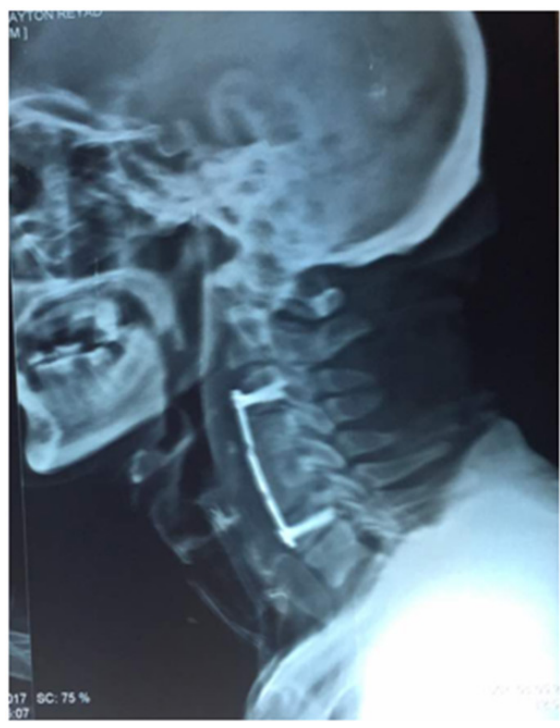

Figure 3 Postoperative cervical plain $X$ ray lateral view, 2 months after the operation, showing the placing of the fixation system, adequate fusion of the graft with above and below vertebrae and stabilization by showing no kyphosis.

Changes in the vertebrae like destruction and collapse, paraspinal abscesses, vertebral metastases, degenerative changes, hematoma should also be considered in differential diagnosis. ${ }^{6,10}$ The regimen that was followed in medical antibiotic therapy was ceftriaxone and vancomycin for about 15 days. ${ }^{3}$ The patient showed no improvement and the neurological deficits showed progressive course, that get the surgical intervention for the surgical evacuation is a must. In 2001, Pina et al., ${ }^{9}$ published paper showing four cases of cervical epidural abscesses and reported the surgical intervention because of worsening neurological status. ${ }^{9}$

In our case, surgical intervention for evacuation of pus via anterior approach and corpectomy of the $\mathrm{C} 4$ and $\mathrm{C} 5$, iliac crest graft with plate and screws fixation was done. ${ }^{11-14}$ Many are believed nowadays that the cervical epidural abscesses are best managed with bony decompression followed by internal stabilization in purulent osteomyelitis and usually by anterior fusion..$^{5,12,15}$ While the need for instrumental stabilization remains questionable when predominant problem is the abscess. In 2016, Shiban et al., ${ }^{11}$ reported the safety of instrumentation devices of fixation in patients suffering from pyogenic spinal infections. ${ }^{11}$

\section{Conclusion}

Because it is a rare condition, suspicion of presence of cervical epidural abscess is crucial to be considered in patients who present with persistent neck pain even with negative history of previous surgical acupuncture nor surgery. Also physicians and neurosurgeons must search for the most important risk factors for occurrence of the 
spinal abscesses like diabetes mellitus, renal impairment, immunity deficiency diseases, addiction, malignancies, laryngeal surgery or dental surgery. The more early diagnosis and management, the better prognosis and results that can be gained.

\section{Conflicts of interest}

No conflict of interest relevant to this article was reported.

\section{Acknowledgements}

None.

\section{Funding}

None.

\section{References}

1. Hadjipavlou AG, Mader JT, Necessary JT, et al. Hematogenous pyogenic spinal infections and their surgical management. Spine. 2000;25(13):1668-1679.

2. Luzzati R, Giacomazzi D, Danzi MC, et al. Diagnosis, management and outcome of clinically suspected spinal infection. $J$ Infect. 2009;58(4):259-265.

3. Mackenzie AR, Laing RB, Smith CC, et al. Spinal epidural abscess: the importance of early diagnosis and treatment. $J$ Neurol Neurosurg Psychiatry. 1998;65(2):209-212.

4. Ju MW, Choi SW, Kwon HJ, et al. Treatment of spinal abscess and predisposing factors of motor weakness: experience with 48 patients. Korean J Spine. 2015;12(3):124-129.

5. Lee JS, Ryu JH, Park JT, et al. Quadriplegia caused by an epidural abscess occurring at the same level of cervical destructive spondyloarthropathy: a case report. BMC Musculoskeletal Disorders. 2017;18(1):11.
6. Kim DM, Kim SW. Destruction of the C2 body due to cervical actinomycosis: connection between spinal epidural abscess and retropharyngeal abscess. Korean J Spine. 2017;14(1):20-22.

7. Kim DM, Kim SW. Gas-containing cervical epidural abscess accompanying bacterial meningitis in an adult. Korean $J$ Spine. 2017;14(1):17-19.

8. Resorlu H, Sacar S, Inceer BS, et al. Cervical spondylitid and epidural abscess caused by brucellosis: a case report and literature review. Folia Medica. 2016;58(4):289-292.

9. Pina MA, Ara JR, Modrego PJ, et al.Brucellar spinal epidural abscess. European journal of neurology. 1999;6(1):87-89.

10. Sebben AL, Graells XS, Benato ML, et al. High cervical spine spondylodiscitis management and literature review. Rev Assoc Bras. 2017;63(1):18-20.

11. Shiban E, Janssen I, da Cunha PR, et al. Safety and efficacy of polyetheretherketone (PEEK) cages in combination with posterior pedicel screw fixation in pyogenic spinal infection. Acta Neurochir (Wien). 2016; 158(10):1851-1857.

12. Shweikeh F, Hussain M, Sangtani A, et al. Cervical spine epidural abscess: a single center analytical comparison to the literature. Spinal cord series and cases. 2017;3:17036.

13. Suess O, Weise L, Brock M, et al. Debridement and spinal instrumentation as a single-stage procedure in bacterial spondylitis/spondylodiscitis. Zentralbl Neurochir. 2017;68(3):123-132.

14. Rigamonti D, Liem L, Wolf Al, et al. Epidural abscess in the cervical spine. Mt Sinai J Med. 1994; 61(4):357-362.

15. Lee JK, Kim SH, Kim ES, et al. Surgical treatment of the spontaneous spinal epidural abscess. J Korean Neurosurg Soc. 2000;29:1037-1042. 